J. Egypt. Soc. Parasitol. (JESP), 51(2), 2021: 355 - 364

(Online: 2090-2549)

\title{
THE EFFECTS OF TWO ANTIPSYCHOTIC DRUGS AND PROLACTIN ON TOXOPLASMA GONDII TACHYZOITES IN VIVO
}

\author{
By \\ ASMAA H. DEEB* ${ }^{*}$ ABD-ALLAH ABD-ELSAMEE HASSAN, \\ MOHAMED E. M. TOLBA and ENAS A. HUSEEIN \\ Department of Medical Parasitology, Faculty of Medicine, Assiut University, \\ Egypt (*Correspondence:mdeep2011@aun.edu.eg)
}

Abstract

Chronic toxoplasmosis is associated with psychotic disorders. Multiple in vitro studies showed that many antipsychotic medications have anti-Toxoplasma activity. Meanwhile, there is very limited data regarding the inhibitory effect of them on Toxoplasma in vivo. This study evaluated the activity of Chlorpromazine ${ }^{\circledR}$, Clozapine $^{\circledR}$, and prolactin (a pituitary gland hormone) on toxoplasmosis infected rats.

Clean laboratory breed rats were chronically infected with non-virulent $T$. gondii strain and classified into 8 groups: negative, positive control groups, chlorpromazine, clozapine, and metoclopramide drug control groups, and 3 infected treated groups. Rats' sera were screened with ELISA test to evaluate level of dopamine, interferon gamma, and prolactin. All drugs were effective against $T$. gondii in infected rats. Dopamine level and INF- $\gamma$ level were significantly decreased in chlorpromazine infected treated rats. There was significant decrease of dopamine level and increase of prolactin level in clozapine infected treated rats. In metoclopramide infected treated rats prolactin level significantly increased, but INF- $\gamma$ level significantly decreased.

Key words: Rats, Toxoplasma gondii, Antipsychotic drugs, ELISA,

\section{Introduction}

Toxoplasma gondii is a zoonotic intracellular protozoan parasite of worldwide distribution infected many species of warm-blooded animals, including birds (Dubey and Beattie, 1988). T. gondii effects were not due to manipulation in an evolutionary sense but, to its neuropathological or neuroimmunological effects (Fond et $a l, 2013)$. Although the medical profession treated these latent cases as asymptomatic and clinically unimportant, results of animal studies and recent studies of personality profiles, behavior, and psychomotor performance led to reconsider this assumption (Flegr, 2013). Epidemiological and neurobiological studies indicated that schizophrenic toxoplasmosis was the second strongest associated after autism (Flegr, 2020). Also, rodents chronic infection with $T$. gondii increased dopamine and metabolite (Ihara et al, 2016), a neurotransmitter involved in human schizophrenia (Mahmoud et al, 2017).

There were complex mechanisms including immune, humoral, neurotransmitter, epigenetic, genetic, and structural effects (Sorlozano-Puerto, 2016). Psychiatric disorders were mostly mediated by brain immune reaction to $T$. gondii infection affected glutamatergic systems, and $T$. gondii biochemical activity affected dopaminergic systems (Flegr, 2015).

The first antipsychotic inhibition of $T$. gondii was an in-vitro study using phenothiazine trifluoperazine (Stelazine), which have membrane-active detergent-like effects on T. gondii (Pezzella et al, 1997). Other in vitro studies of different antipsychotics and mood stabilizer drugs compared their inhibitory effect on $T$. gondii against trimethoprim effectiveness, the standard toxoplasmosis treatment (Jones-Brando et al, 2003; Goodwin et al, 2008; Fond et al, 2014). Many antipsychotics inhibited cultured Toxoplasma (Goodwin et al, 2011), but with few limited data on $T$. gondii in vivo (Saraei et al, 2016).

Hyperprolactinemia is a common side effect of antipsychotics, and prolactin is one of the most important human hormones in immuno-regulation (López-meza et 
$a l, 2010)$. Prolactin inhibited the multiplication of Toxoplasma in murine microglial cell cultures (Benedetto et al, 2001), and significantly restricted Toxoplasma intracellular growth in mice and human cell lines (Dzitko et al, 2010; 2012). Women with hyperprolactinemia had few $T$. gondii prevalence rate (Dzitko et al, 2008). Also, $T$. gondii-induced intermediate host behavior alterations and parasite transmission and with postulated relationship between its sero-prevalence and infection in certain disorders such as human schizophrenia (Gatkowska et al, 2013).

The present study aimed to evaluate the possible role of antipsychotic drugs and hyperprolactinemia in controlling toxoplasmosis in experimental animal models.

\section{Materials and Methods}

This experimental study was conducted from January 2018 to December 2019 according to the ethical rules of dealing with experimental animals.

Drugs: Chlorpromazine (CHZ) (Neurazine, coated tablet manufactured by Misr Pharmaceutical Co., Cairo) as the typical antipsychotics at dose of $30 \mathrm{mg} / \mathrm{kg} / \mathrm{day}$ (Tse et al, 2018). Clozapine (CLZ) (Clozaril, coated tablet supplied by Novartis Co., Cairo) as another typical antipsychotics at dose of $5 \mathrm{mg} / \mathrm{kg} /$ day (Sun and Lau, 2000). Metoclopramide (MTP) (Primpran, coated tablet supplied by Sanofi Aventis Co., Cairo) a prokinetic drug used in nausea, vomiting, diabetic gastric stasis and gastro-esophageal reflux, is a potent stimulator of prolactin release at dose of $5 \mathrm{mg} /$ $\mathrm{kg} /$ day (Uchida et al, 2005). Drugs were separately grinded, dissolved in Ringer's solution and given orally to Wistar Rats.

Experimental animals: Clean laboratory bred Wister Rats 40days old \& about 130 gm each maintained in animal house, Faculty of Medicine was used. The Rh strain of Toxoplasma gondii tachyzoites as peritoneal exudate of mice used was kindly obtained from Department of Zoonotic Diseases, National Research Center, Dokki
Rats were intra-peritoneally infected with $5 \times 10^{6}$ tachyzoites. All experiments were done between $6 \& 8$ weeks' post-infection (Dubey et al, 2016). Rats were divided into eight groups of 6 rats each and housed in separate metallic cage with free access to food \& water. GI: Negative control, neither infected nor treated. GII: Positive control only infected. GIII: Chlorpromazine, GIV: Clozapine \& GV: Metoclopramide only treated positive drug controls. GVI: Infected \& chlorpromazine treated with an oral dose of $\mathrm{CHZ}$ daily for 3 weeks on the $8^{\text {th }}$ week post-infection (PI). GVII: Infected $\&$ clozapine treated with an oral dose of CLZ daily for 3 weeks on the $8^{\text {th }}$ week PI. GVIII: Infected \& metoclopramide treated with MTP daily for 3 weeks on the $8^{\text {th }}$ week PI.

Blood was obtained from rats' orbital sinus 60 days P.I. and sera were tested for $T$. gondii- IgG antibodies by modified agglutination test (MAT) to ensure infectivity (Mainar-Jaime and Barberán, 2007).

Histopathological examination: After $3^{\text {rd }}$ week post-treatment, rats were intraperitoneally injected with xylazine/ketamine anesthesia (Nelissen et al, 2019), and sacrificed by cervical dislocation to prevent preand postsynaptic effects of anesthesia, and brains were quickly removed. Portions of brain were fixed in buffered formalin, embedded in paraffin, sectioned, and stained with hematoxylin \& eosin and examined under low, high and oil immersions.

Neurotransmitter and biochemical markers: Levels of serum dopamine (DA), serum interferon gamma INF- $\gamma$ \& serum prolactin PRL of all rats were done by ELISA with antibody pairs of Sino-Gene-ClonBiotech Co., Ltd (Hangzhou, China Catalog No: SG-20553, No: SG-20041\& No: SG20835). Technique was processed according to the manufacturer given protocol.

Statistical analysis: Data were collected, tabulated, and analyzed by using SPSS version 24. ANOVA \& post-hoc tested variance analysis $\&$ significance. $P$ value less 
than 0.05 were considered significant.

\section{Results}

Infectivity: Sera of all infected rats tested for $T$. gondii-specific IgG antibodies by modified agglutination test (MAT) before and after treatment. All showed positive results before receiving drugs. While all sera showed negative result after therapy.

Microscopic examination of negative and drugs controls showed brain parenchyma with unremarkable pathological findings. Positive controls showed infected cerebral parenchyma by tachyzoites were few, vacuolar degeneration was marked in infected cells and sparse inflammatory cells were detected. Infected chlorpromazine treated (CHZ) showed brain paren- chyma with unremarkable pathological findings. Infected clozapine treated and metoclopramide treated ones showed brain parenchyma with vacuolar degeneration and multiple inflammatory cell infiltration including eosinophilic cells.

Biochemistry data: Dopamine (DA) level was significantly increased in positive control as compared to negative ones. All drug control groups showed significantly increased DA level as compared to negative control in chlorpromazine (CHZ) and clozapine (CLZ) infected treated groups DA level significantly decreased compared to positive control.

Details were given in tables $(1,2 \& 3)$ and figures $(1,2,3 \& 4)$.

Table 1: Dopamine level (ng/L) difference between groups.

\begin{tabular}{|l|l|l|l|l|}
\hline Groups & Mean \pm SD & Median (IQR) & P value \\
\hline \multirow{2}{*}{ Control } & Negative control & $10.05 \pm 0.7$ & $10(1)$ & \\
\cline { 2 - 4 } & Positive control & $26.45 \pm 9.4$ & $24(18)$ & \\
\hline \multirow{3}{*}{$\begin{array}{c}\text { Control } \\
\text { Treated }\end{array}$} & CHZ treated & $22.20 \pm 0.6$ & $22.5(1)$ & \\
\cline { 2 - 4 } & CLZ treated & $16.42 \pm 0.7$ & $17(1)$ & \\
\cline { 2 - 4 } & MTP treated & $16.75 \pm 0.7$ & $17(1)$ & \\
\hline \multirow{3}{*}{$\begin{array}{l}\text { Infected } \\
\text { Treated }\end{array}$} & CHZ treated & $18.27 \pm 0.6$ & $18(1)$ & \\
\cline { 2 - 4 } & CLZ treated & $19.37 \pm 5.9$ & $18.5(11)$ & \\
\cline { 2 - 4 } & MTP treated & $20.77 \pm 8.9$ & $17.5(6)$ & \\
\hline \multirow{4}{*}{ P-value } & GI vs. GII $<0.001$ & GI vs. GVI $=0.008$ & GII vs. GVII $=0.018$ & \\
\cline { 2 - 4 } & GI vs. GIII $<0.001$ & GI vs. GVII $=0.003$ & GII vs. GVIII $=0.059$ & \\
\cline { 2 - 4 } & GI vs. GIV $=0.035$ & GI vs. GVIII $=0.001$ & GIII vs. GVI $=0.186$ & \\
\cline { 2 - 4 } & GI vs. GV $=0.027$ & GII vs. GVI $=0.008$ & GV vs. GVIII $=0.177$ & \\
\hline
\end{tabular}

There was a significant increase in INF- trols, while CLZ rats showed significant $\gamma$ level in positive control as compared to negative one. $\mathrm{CHZ} \&$ MTB positive controls showed significant decrease of INF- $\gamma$ level as compared to their negative conincrease. But, in chlorpromazine (CHZ) and (MTB) infected treated INF- $\gamma$ level significantly decreased compared to their positive controls.

Table 2: INF-Y level (ng/L) difference between groups.

\begin{tabular}{|c|c|c|c|c|}
\hline \multicolumn{2}{|l|}{ Groups } & Mean \pm SD & Median (IQR) & $\mathrm{P}$ value \\
\hline \multirow{2}{*}{ Control } & Negative control & $12.10 \pm 2.1$ & $10(1.5)$ & \multirow{8}{*}{$<0.001$} \\
\hline & Positive control & $20.47 \pm 4.9$ & $20(8.5)$ & \\
\hline \multirow{3}{*}{$\begin{array}{l}\text { Treated } \\
\text { Control }\end{array}$} & $\mathrm{CHZ}$ treated & $5.63 \pm 0.6$ & $6(1)$ & \\
\hline & CLZ treated & $38.48 \pm 1.1$ & $39(2.5)$ & \\
\hline & MTP treated & $2.38 \pm 0.5$ & $2.5(1)$ & \\
\hline \multirow{3}{*}{$\begin{array}{l}\text { Treated } \\
\text { Infected }\end{array}$} & CHZ treated & $11.42 \pm 1.2$ & $13.5(6.5)$ & \\
\hline & CLZ treated & $20.00 \pm 2.6$ & $21(8.5)$ & \\
\hline & MTP treated & $13.57 \pm 2.3$ & $15(6.5)$ & \\
\hline \multirow{4}{*}{ P-value } & GI vs. GII $=0.005$ & GI vs. GVI $=0.811$ & GII vs. GVII $=0.870$ & GIV vs. GVII $<0.001$ \\
\hline & GI vs. GIII $=0.028$ & GI vs. G VII $=0.008$ & GII vs. G VIII $=0.020$ & \\
\hline & GI vs. GIV $<0.001$ & GI vs. GVIII $=0.608$ & GIII vs. GVI $=0.048$ & \\
\hline & GI vs. $G V=0.001$ & GII vs. GVI $=0.003$ & GV vs. GVIII $<0.001$ & \\
\hline
\end{tabular}

There was a significant decrease in PRL level in sera of positive control as compared to negative one. All drug positive controls showed significant increase in
PRL level as compared to negative control All infected treated rats showed significant increase in PRL level compared to each positive control rats. 
Table 3: Prolactin level $(\mathrm{ng} / \mathrm{mL})$ difference between groups

\begin{tabular}{|c|c|c|c|c|}
\hline \multicolumn{2}{|l|}{ Groups } & Mean \pm SD & Median (IQR) & $P$ value \\
\hline \multirow{2}{*}{ Control } & Negative control & $16.07 \pm 1.1$ & $16(1.5)$ & \multirow{8}{*}{$<0.001$} \\
\hline & Positive control & $12.08 \pm 1.6$ & $12(3)$ & \\
\hline \multirow{3}{*}{$\begin{array}{l}\text { Control } \\
\text { Treated }\end{array}$} & CHZ treated & $26.55 \pm 2.6$ & $26.5(2)$ & \\
\hline & CLZ treated & $50.43 \pm 5.3$ & $50.5(2.5)$ & \\
\hline & MTP treated & $56.60 \pm 4.2$ & $56.5(2)$ & \\
\hline \multirow{3}{*}{$\begin{array}{l}\text { Infected } \\
\text { Treated }\end{array}$} & $\mathrm{CHZ}$ treated & $17.22 \pm 1.6$ & $17.5(3)$ & \\
\hline & CLZ treated & $25.52 \pm 4.3$ & $26(8.5)$ & \\
\hline & MTP treated & $33.98 \pm 2.2$ & $33.5(3.5)$ & \\
\hline \multirow{4}{*}{ P-value } & GI vs. GII $=0.002$ & GI vs. GVI $=0.339$ & GII vs. GVII $<0.001$ & GIV vs. GVII < 0.001 \\
\hline & GI vs. GIII $<0.001$ & GI vs. GVII $<0.001$ & GII vs. GVIII $<0.001$ & \\
\hline & GI vs. GIV $<0.001$ & GI vs. GVIII $<0.001$ & GIII vs. GVI < 0.001 & \\
\hline & GI vs. GV $<0.001$ & GII vs. GVI < 0.001 & GV vs. GVIII < 0.001 & \\
\hline
\end{tabular}

\section{Discussion}

No doubt, RH strain, passed for $50+\mathrm{yr}$ as tachyzoites lost not only oocysts capacity formation, but also showed a reduction or absence of tissue cyst (bradyzoites) formation (Dubey et al, 1999)

In the present study, chlorpromazine, clozapine, and metoclopramide were effective against $T$. gondii, with the antipsychotic $\mathrm{CHZ}$ gave the best impact even with small used dose that caused small prolactin elevation. $\mathrm{CHZ}$ is a dopamine $\mathrm{D} 2$ receptor antagonist with significant anticholinergic/alpha-adrenergic blocking activity (Kapur, 2003). Association between toxoplasmosis and increased level of dopamine (DA) in brains of animal model contained two genes for enzyme tyrosine hydroxylase (Flegr et al, 2003), the key enzyme for the DA synthesis from its precursor and could release it into surrounding tissue of infected animal and also man (Skallová et al, 2005; Wang et al, 2015).

In the CHZ infected treated group, DA level significantly decreased compared to infected control group. This might be related to the feedback regulation effect of dopamine level which means improvement of symptoms caused by toxoplasmosis.

In the present study, INF- $\gamma$ level significantly decreased in $\mathrm{CHZ}$ infected treated rats compared to corresponded control, but significantly increased compared to the $\mathrm{CHZ}$ drug control. CHZ independently down-regulated production of various $\mathrm{T}$ cell-derived lymphokines (IL-2, IFN- $\gamma$,
IL-4, TNF, \& GM-CSF) and up-regulated the secretion of IL-10 (Tarazona et al, 1995). However, T. gondii infection led to host immune response, production of proinflammatory cytokines, activates Th-cells that secrete IFN- $\gamma$; a major cytokine mediates resistance against it (Suzuki et al, 1988). So, the present result showed a direct effect of the drug itself on the INF- $\gamma$ level. But, the most convincing conception that $\mathrm{CHZ}$ inhibited replication of $T$. gondii tachyzoites, without significant difference between the INF- $\gamma$ levels in infected CHZ treated rats and corresponded negative control. Besides, PRL level significantly increased in $\mathrm{CHZ}$ infected treated compared to infected control. PRL is inversely proportional with Toxoplasma human positivity that increased excretion correlated with decreased toxoplasmosis prevalence and vice versa (Dzitko et al, 2008).

No doubt, $\mathrm{CHZ}$ is the most dependable effective drug control experimentally induced toxoplasmosis is not just neurotransmitter results but also MAT, detects of $T$. gondii $\operatorname{IgG}$ antibodies, converted negative in sera of all infected rats after therapy. Besides, unremarkable pathological findings were revealed in rats' brain parenchyma, rather than other drug tested.

The inhibitory effect of $\mathrm{CHZ}$ drug on Toxoplasma infection in the present study agreed with similar previous findings in different in vitro studies. It was found that the valproate (mood-stabilizing agent) and haloperidol may have respectively a higher in vitro anti-toxoplasmic activity com- 
pared to trimethoprim. While chlorpromazine and fluphenazine showed some activity but less than trimethoprim (JonesBrando et al, 2003). This result was further replicated in animal models that showed improvement in the suicidal attempts in rats (Webster et al, 2006). A partial replication of this study was carried out using some different methods and assays. In this study, haloperidol and valproic acid had no measurable effect, but fluphenazine, thioridazine, and trifluoperazine did (Goodwin et al, 2008; 2011). Also, Fond et al. (2014) showed that fluphenazine and zuclopenthixol possessed a good inhibition of $T$. gondii, whereas haloperidol, levomepromazine, and loxapine had a fair inhibition. However, the result was conflicted with in-vivo study of Saraei et al. (2016), who reported that thioridazine and fluphenazine could not significantly inhibited brain cystogenesis of $T$. gondii in mice. Only, each of them reduced insignificantly the percent of cysts at higher dose compared to lower one.

CHZ acted by directly minimizing $T$. gondii replication and invasion of host brain cells in vitro (Jones-Brando et al, 2003), anti-T. gondii activity was related to drug calcium inhibitory properties (Ballejo et al, 1986).

T. gondii tachyzoites require calcium to invade host cells, and this invasion is inhibited by calcium channel blockers and calmodulin antagonists, including trifluoperazine, another phenothiazine antipsychotic (Pezzella et al, 1997; Carruthers et $a l, 1999)$. Transient rises in intracellular calcium within tachyzoites serve as a trigger for parasite egress from host cells and participate in the cell gliding motility and host-cell invasion processes (Nagamune et al, 2008; Lourido et al, 2010). Calmodulin may apply its role in invasion by mediating calcium-dependent conoid extrusion and through calcium-stimulated lytic enzymes secretion at the attachment site on the host cell. In these ways, calmodulin inhibition would suppress tachyzoite invasion and protect host cell monolayers (Pezzella et al, 1997).

One could propose that CHZ's superior therapeutic impact here may be through a combination of both its ability to inhibit replication of $T$. gondii and to decrease, directly and indirectly, dopamine levels.

In the present study, clozapine gave moderate anti-Toxoplasma activity as biochemical findings showed a significant decrease of DA level and increase of prolactin level in comparing CLZ infected treated rats with the infected control ones. Moreover, MAT became negative after three weeks' therapy and brain histopathology revealed inflammatory cells and vacuolar degeneration without tachyzoite cyst.

CLZ is the prototype agent in Secondgeneration (atypical) antipsychotic drugs. These drugs target the dopamine D2 receptor, as well as the serotonin receptor, and, as a class, bind less tightly to the dopamine receptor than typical antipsychotics (Miyamoto et al, 2005; Seeman, 2002). Also, it is adrenergic $(\alpha 1)$, histaminergic (H1), and muscarinic acetylcholine receptor antagonist (Kapur and Remington, 2001). Consequently, it also increases PRL secretion (Kuroki et al, 2008).

The present study showed that CLZ high significantly increased INF- $\gamma$ level compared to CLZ drug control with negative control rats. Also, it significantly decre-ased CLZ infected treated rats compared to its drug control. But, the INF- $\gamma$ level showed an insignificant result in comparing CLZ infected treated rats to the positive control ones. Song et al. (2000) in vitro showed that with a different concentration of CLZ had a different effect on cytokine production by human whole blood. CLZ $10^{-6} \& 10^{-8} \mathrm{M}$ (microliter) significantly increased the unstimulated and stimulated production of IL-1RA (receptor antagonist). The CLZ $10^{-6} \mathrm{M}$ significantly increased the IFN- $\gamma$ production, which led to intracellular degradation of tryptophan 
by the host cell and restricted the $T$. gondii growth in two ways (Vogel et al, 2014). Tryptophan metabolites were toxic to the parasite in a manner that was reversible by tryptophan. Degradation tryptophan reduced its concentration in host cell and the intracellular parasites would lack essential amino acid (Goodwin et al, 2011). This agreed with in vitro study of Jones-Brando et al. (2003) who found that risperidone, clozapine, \& quetiapine (mood-stabilizing agent) had moderate anti-toxoplasmosis activity less than trimethoprim. A partial replication of this study was done using different methods and assays. In this study, clozapine had no measurable effect (Goodwin et al, 2008; 2011). But, in another study, amisulpride, risperidone and valproic acid showed poor Toxoplasma inhibition (Fond et al, 2014). The present study disagreed with Saraei et al. (2015), who reported that aripiprazole had no inhibitory effect on brain cystogenesis of $T$. gondii ME49 strain explained that by second generation antipsychotics were not calmodulin antagonists, and even some cellular actions of clozapine showed dependence upon calmodulin, a prototypical calcium sensor (Chin and Means, 2000) activated kinase activity (Shin et al, 2006).

In the present study, no reason was to exclude the idea that actions of atypical antipsychotics drugs on ion channels also contribute to inhibition of tachyzoite propagation in host cells. Multiple mechanisms may be at work here. CLZ exhibits anti-inflammatory activity through the inhibition of calcium/calmodulin-dependent Akt, alpha serine/threonine-protein kinase, activation in microglia (Jeon et al, 2018), which results in the inhibition of cell cycle progression (Shin et al, 2006). Clozapine increase host cell cytosolic $\mathrm{Ca}^{2+}$ and thus significantly decreased tachyzoite invasion (Pezzella et al, 1997). In-vivo, the intracellular $\mathrm{Ca}^{2+}$ increased concentration via up-regulation of neuronal $\mathrm{Ca}$ sensors, such as visinin-like protein 1 (VILIP-1) \& neurocalcin $\delta$ (NCALD) (Kedracka-Krok et al, 2015).

Metoclopramide MTP is a potent dopamine receptor antagonist but does not affect the central DA. It abolishes the inhibitory effect of dopamine on the PRL secretion that led to PRL level increase (Dzitko et al, 2008).

In the present study, MTB gave a moderate inhibitory effect in $T$. gondii by significant increased prolactin level, and decreased INF- $\gamma$ level, with insignificant decreased dopamine. But, MAT became negative after three weeks where brain showed inflammatory cells and vacuolar degeneration without tachyzoites. MTP increased the PRL level and stimulated Th1 cytokine production, especially IFN- $\gamma$ excretion (Matalka, 2003). MTP acted as an immunomodulating agent with release cytokines by macrophage as IL-1 \& IL-6 (Abd Ellah et al, 2019).

Based on present study data, higher levels of the prolactin in patients' sera may restrict the $T$. gondii tachyzoites growth. But, this disagreed with Mavoungou (2006) who found that prolactin concentration did not differ according to $P$. falciparum status, despite its increase during pregnancy, regardless of parity. Also, Dzitko et al. (2008) reported increased prevalence of latent toxoplasmosis in women with an aberrant level of prolactin. However in favor of the present study, the pre-incubation of Toxoplasma tachyzoites with the recombinant human prolactin (rhPRL) in vitro caused a significant reduction (up to $36.15 \%$ ) in its replication abilities due to a limited parasites capacity to penetrate human cells (Hs27 y HeLa) as noticed by reduced number of infected cells (Dzitko et al, 2010). Besides, Dzitko et al. (2012) found a significant increase in serum PRL level during pregnancy limited $T$. gondii spreading, and exogenous human recombinant prolactin (rhPRL) \& autologous endogenous prolactin (sPRL) from inactivated sera significantly restrict- 
ed Toxoplasma intracellular growth in peripheral blood cultures. T. gondii replication was reduced in murine L929 cells prolactin treated with (Dzitko et al, 2013). Protective immune response of man and animal infected with intracellular pathogens as $T$. gondii was based mainly on IFN- $\gamma$ synthesis (Denkers, 2003). PRL may play a role similar to IFN- $\gamma$, because, alone or together with TNF- $\alpha$, it stimulates the intracellular killing of the parasite (Benedetto et al, 1995). Also, PRL at a normal physiological concentration enhanced IFN- $\gamma$ production in NK cells (Matera et al, 1999). It stimulated Th1 cytokine production, especially IFN- $\gamma$ excretion, by mononuclear cells, due to activation of interferon regulator factor-1 (Peeva et al, 2004). But, PRL induced the secretion of cytokines such as IL-6 \& IL-10, a cytokine with a broad immunoregulatory activity that controls an inflammatory response during acute toxoplasmosis. Also, cytokine is a unique product of $\mathrm{Th}_{2}$ lymphocytes, antagonizes many effects of IFN$\gamma$ (Lang et al, 2007). So, possible PRL action could be bidirectional, namely, PRL limited Toxoplasma proliferation via surface host cell receptors (Dzitko et al, 2013) led to release of protective type-1 cytokines (Matalka, 2003), and inhibited penetration ability (Dzitko et al, 2010).

\section{Conclusion}

Antipsychotic chlorpromazine drug has good anti-Toxoplasma activity in rat. Psychotropic drugs for anti-Toxoplasma activity in schizophrenic patients might improve prognosis and treatment efficacy. Exact mechanism of interaction between hormone, host cell, and parasite is still unknown. Chlorpromazine may affect $T$. gondii.

\section{Acknowledgement}

The authors are grateful to the Grants Office, Faculty of Medicine, Assiut University for the fund June 2017; Code 2016/ 08/30-005-R3.

Authors Contributions: All authors equally contributed in this study

\section{References}

Abd Ellah, NH, Ahmed, EA, Abd-Ellatief, RB, Ali, MF, Zahran, AM, et al, 2019: Metoclopramide nanoparticles modulate immune response in a diabetic rat model: Association with re-gulatory $\mathrm{T}$ cells and proinflammatory cytokines. Inter. J. Nanomed. 4:2383-95.

Dubey, JP, Beattie, CP, 1988: Toxoplasmosis of Animals and Man. CRC Press, Boca Raton, FL.

Ballejo, G, Calixto, JB, Medeiros, YS, 1986: In vitro effects of calcium entry blockers, chloropromazine and fenoterol upon human pregnant myometrium contractility. Br. J. Pharmacol. 89, 3:515-23.

Benedetto, N, Folgore, A, Galdiero, M, Meli, R, Di Carlo, R, 1995: Effect of prolactin, rIFN-gamma or rTNF-alpha in murine toxoplasmosis. Pathol-Biol. 43, 5:395-400.

Benedetto, N, Folgore, A, Romano CarrateIli, C, Galdiero, F, 2001: Effects of cytokines and prolactin on the replication of Toxoplasma gondii in murine microglia. Euro. Cytok. Network 12, 2:348-58.

Carruthers, VB, Moreno, SN, Sibley, LD, 1999: Ethanol and acetaldehyde elevate intracellular $[\mathrm{Ca} 2+]$ and stimulate microneme discharge in Toxoplasma gondii. Biochem. J. 342, Pt 2:379-86.

Chin, D, Means, AR, 2000: Calmodulin: a prototypical calcium sensor. Trends Cell Biol. 10, 8:322-8.

Denkers, EY, 2003: From cells to signaling cascades: manipulation of innate immunity by Toxoplasma gondii. FEMS Immunol. Med. Microbiol. 39 No. 3:193-203.

Dubey, JP, Shen, SK, Kwok, OC, Frenkel, JK, 1999: Infection and immunity with the RH strain of Toxoplasma gondii in rats and mice. J. Parasitol. 85, 4:657-62.

Dubey, JP, Ferreira, LR, Alsaad, M, Verma, SK, Alves, DA, et al, 2016: Experimental toxo-plasmosis in rats induced orally with eleven strains of Toxoplasma gondii of seven genotypes: Tissue tropism, tissue cyst size, neural lesions, tissue cyst rupture without reactivation, and ocular lesions. PloS One, Public Library of Sci. 11, 5:e0156255.

Dzitko, K, Malicki, S, Komorowski, J, 2008: Effect of hyperprolactinaemia on Toxoplasma gondii prevalence in humans. Parasitol. Res. 102, 4:723-9.

Dzitko, K, Gatkowska, J, Płociński, P, Dzi- 
adek, B, Długońska, H, 2010: The effect of prolactin (PRL) on the growth of Toxoplasma gondii tachyzoites in vitro. Parasitol. Res. 107, 1:199-204.

Dzitko, K, Lawnicka, H, Gatkowska, J, Dziadek, B, Komorowski, J, et al, 2012: Inhibitory effect of prolactin on Toxoplasma proliferation in peripheral blood mononuclear cells from patients with hyperprolactinemia. Parasite Immunol. 34, 6:302-11.

Dzitko, K, Dziadek, B, Gatkowska, J, Długońska, H, 2013: Toxoplasma gondii binds sheep prolactin. Exp. Parasitol. 134, 2:216-9.

Flegr, J, 2013: Influence of latent Toxoplasma infection on human personality, physiology and morphology: Pros and cons of the Toxoplasma-human model in studying the manipulation hypothesis. J. Exp. Biol. 216, Pt1: 127-33.

Flegr, J, 2015: Neurological and neuropsychiatric consequences of chronic Toxoplasma infection. Curr. Clin. Microbiol. Repts. 2, 4: 163-72.

Flegr, J, 2020: Negative effects of latent toxoplasmosis on mental health. Front Psychiat. Feb 18;10:1012 doi:10.3389/fpsyt. 01012

Flegr, J, Preiss, M, Klose, J, Havlícek, J, Vitáková, M, et al, 2003: Decreased level of psychobiological factor novelty seeking and lower intelligence in men latently infected with the protozoan parasite Toxoplasma gondii dopamine, a missing link between schizophrenia and toxoplasmosis? Biol. Psychol. 63, 3:253-68.

Fond, G, Capdevielle, D, Macgregor, A, Attal, J, Larue, A, et al, 2013: Toxoplasma gondii: A potential role in the genesis of psychiatric disorders. Encephale. 39, 1:38-43.

Fond, G, Macgregor, A, Tamouza, R, Hamdani, N, Meary, A, et al, 2014: Comparative analysis of anti-toxoplasmic activity of antipsychotic drugs and valproate. Euro. Arch. Psychiat. Clin. Neurosci. 264, 2:179-83.

Gatkowska, J, Wieczorek, M, Dziadek, B, Dzitko, K, Dlugonska, H, 2013: Sex-dependent neurotransmitter level changes in brains of Toxoplasma gondii infected mice. Exp. Parasitol. 133, 1:1-7.

Goodwin, DG, Strobl, J, Mitchell, SM, Zajac, AM, Lindsay, DS, 2008: Evaluation of the mood-stabilizing agent valproic acid as a preventative for toxoplasmosis in mice and activity against tissue cysts in mice. J. Parasi- tol. 94, 2:555-7.

Goodwin, DG, Strobl, JS, Lindsay, DS, 2011: Evaluation of five antischizophrenic agents against Toxoplasma gondii in human cell cultures. J. Parasitol. 97, 1:148-51.

Hoff, EF, Carruthers, VB, 2002: Is Toxoplasma egress the first step in invasion? Trends Parasitol. 18, 6:251-5.

Ihara, F, Nishimura, M, Muroi, Y, Mahmoud, ME, Yokoyama, N, et al, 2016: Toxoplasma gondii infection in mice impairs longterm fear memory consolidation through dysfunction of the cortex and amygdala. Infect. Immun. 84, 10:2861-70.

Jeon, S, Kim, SH, Shin, SY, Lee, YH, 2018: Clozapine reduces Toll-like receptor 4/NF- $\mathrm{kB}$ -mediated inflammatory responses through inhibition of calcium/calmodulin-dependent Akt activation in microglia. Progr. NeuroPsychopharmacol. Biol. Psychiat. 81:477-87.

Jones-Brando, L, Torrey, EF, Yolken, R, 2003: Drugs used in the treatment of schizophrenia and bipolar disorder inhibit the repliction of Toxoplasma gondii. Schizophrenia Res. 62, 3:237-44.

Kapur, S, 2003: Psychosis as a state of aberrant salience: A framework linking biology, phenomenology, and pharmacology in schizophrenia. Am. J. Psychiat. 160,1:13-23.

Kapur, S, Remington, G, 2001: Dopamine $\mathrm{D}(2)$ receptors and their role in atypical antipsychotic action: still necessary and may even be sufficient. Biol. Psychiat. 50, 11:873-83.

Kedracka-Krok, S, Swiderska, B, Jankowska, U, Skupien-Rabian, B, et al, 2015: Clozapine influences cytoskeleton structure and calcium homeostasis in rat cerebral cortex and has a different proteomic profile than risperidone. J. Neurochem. 132, 6:657-76.

Kuroki, T, Nagao, N, Nakahara, T, 2008: Neuropharmacology of second-generation anti-psychotic drugs: a validity of the serotonindopamine hypothesis. Progr. Brain Res. 172: 199-212.

Lang, C, Gross, U, Lüder, CGK, 2007: Subversion of innate and adaptive immune responses by Toxoplasma gondii. Parasitol. Res. 10, 2:191-203.

López-meza, JE, Lara-zárate, L, Ochoazarzosa, A, 2010: Negative effects of latent toxoplasmosis on mental health. Open Neuroendocrinol. J. 3,1:175-9.

Lourido, S, Shuman, J, Zhang, C, Shokat, 
KM, Hui, R, et al, 2010: Calcium-dependent protein kinase 1 is an essential regulator of exocytosis in Toxoplasma, Nature Publishing Group, Vol. 465 available at:https://doi.org/ 10.1038/nature09022.

Mahmoud, ME, Fereig, R, Nishikawa, Y, 2017: Involvement of host defense mechanisms against Toxoplasma gondii infection in anhedonic and despair-like behaviors in mice. Infect. Immun. 85, 4:1-18.

Mainar-Jaime, RC, Barberán, M, 2007: Evaluation of the diagnostic accuracy of the modified agglutination test (MAT) and an indirect ELISA for the detection of serum antibodies against Toxoplasma gondii in sheep through Bayesian approaches. Vet. Parasitol. 148, 2:122-9.

Matalka, KZ, 2003: Prolactin enhances production of interferon-gamma, interleukin-12, and interleukin-10, but not of tumor necrosis factor-alpha, in a stimulus-specific manner. Cytokine 21, 4:187-94.

Matera, L, Contarini, M, Bellone, G, Forno, B, Biglino, A, 1999: Up-modulation of interferon-gamma mediates the enhancement of spontanous cytotoxicity in prolactin-activated natural killer cells. Immunology 98, 3:386-92.

Matera, L, Mori, M, 2000: Cooperation of pituitary hormone prolactin with interleukin-2 and interleukin-12 on production of interferon-gamma by natural killer and T cells. Ann. New York Acad. Sci. 917:505-13.

Mavoungou, E, 2006: Interactions between natural killer cells, cortisol and prolactin in malaria during pregnancy. Clin. Med. Res. 4,1:33-41.

Miyamoto, S, Duncan, GE, Marx, CE, Lieberman, JA, 2005: Treatments for schizophrenia: A critical review of pharmacology and mechanisms of action of antipsychotic drugs. Mol. Psychiat. 10, 1:79-104.

Nagamune, K, Hicks, LM, Fux, B, Brossier, F, Chini, EN, et al, 2008: Abscisic acid controls calcium-dependent egress and development in Toxoplasma gondii. Nature 451, 7175: 207-10.

Nelissen, E, van Goethem, NP, Bonassoli, V T, Heckman, PRA, van Hagen, BTJ, et al, 2019: Validation of the test as a predictor of the emetic potential of pharmacological compounds in rats. Neurosci. Lett. 699:41-46

Peeva, E, Venkatesh, J, Michael, D, Diamond, B, 2004: Prolactin as a modulator of $B$ cell function: Implications for SLE. Biomed. Pharmacothera. France 58, 5:310-9.

Pezzella, N, Bouchot, A, Bonhomme, A, Pingret, L, Klein, C, et al, 1997: Involvement of calcium and calmodulin in Toxoplasma gondii tachyzoite invasion. Euro J. Cell Biol. 74,1:92-101.

Saraei, M, Ghaderi, Y, Mosavi, T, Shahnazi, M, Nassiri-Asl, M, et al, 2016: The effect of fluphenazine and thioridazine on Toxoplasma gondii in vivo. Iran. J. Parasitol. Tehran Univ. Med. Sci. 11, 2:226-31.

Saraei, M, Samadzadeh, N, Khoeini, J, Shahnazi, M, Nassiri-Asl, M, et al, 2015: In vivo anti-Toxoplasma activity of aripiprazole. Iran. J. Basic Med. Sci. 18, 9:938-41.

Seeman, P, 2002:Atypical antipsychotics: Mechanism of action. Cana. J. Psychiat. 47, 1: 27-38.

Shin, SY, Choi, BH, Ko, J, Kim, SH, Kim, YS, et al, 2006: Clozapine, a neuroleptic agent, inhibits Akt by counteracting $\mathrm{Ca} 2+/ \mathrm{calm}$ odulin in PTEN-negative U-87MG human glioblastoma cells. Cell. Signalling 18, 11:187686.

Song, C, Lin, AH, Kenis, G, Bosmans, E, Maes, M, 2000: Immunosuppressive effects of clozapine and haloperidol: Enhanced production of the interleukin-1 receptor antagonist. Schizophrenia Res. 42, 2:157-64.

Sorlozano-Puerto, A, 2016: Toxoplasma gondii \& schizophrenia. In: A Relationship That Is Not Ruled Out. Shen, JGFEYC. (Ed.), IntechOpen, Rijeka.

Sun, L, Lau, CE, 2000: Intravenous and oral clozapine pharmacokinetics, pharmacodynamics, and concentration-effect relations: Acute tolerance. Euro. J. Pharmacol. 398, 2:225-38.

Suzuki, Y, Orellana, MA, Schreiber, RD, Remington, JS, 1988: Interferon-gamma, major mediator of resistance against Toxoplasma gondii. Science N.Y. 240, 4851:516-8.

Tarazona, R, González-García, A, Zamzami, N, Marchetti, P, Frechin, N, et al. 1995: Chlorpromazine amplifies macrophage-dependent IL-10 production in-vivo. J. Immunol. 154, 2:LP861-70.

Tse, K, Sillito, R, Keerie, A, Collier, R, Grant, $C$, et al, 2018: Pharmacological validation of individual animal locomotion, temperature and behavioural analysis in group-housed rats using a novel automated home cage analysis system: A comparison with the mod- 
ified Irwin test. J. Pharmacol. Toxicol. Meth. 94:1-13.

Uchida, M, Endo, N, Shimizu, K, 2005: Simple and noninvasive breath test using $13 \mathrm{C}$ acetic acid to evaluate gastric emptying in conscious rats and its validation by metoclopramide. J. Pharmacol. Sci. 98,4:388-95.

Vogel, DYS, Glim, JE, Stavenuiter, AWD, Breur, M, Heijnen, P, et al, 2014: Human macrophage polarization in vitro: Maturation and activation methods compared. Immunobiology 219, 9:695-703.

Wang, ZT, Harmon, S, O'Malley, KL, Sibley, LD, 2015: Reassessment of the role of aromatic amino acid hydroxylases and the effect of infection by Toxoplasma gondii on host dopamine. Infect. Immun. 83, 3:1039-47.

Webster, JP, Lamberton, PHL, Donnelly, C A, Torrey, EF, 2006: Parasites as causative agents of human affective disorders? The impact of anti-psychotic, mood-stabilizer and anti-parasite medication on Toxoplasma gondii's ability to alter host behaviour. Proceed. Biol. Sci. 273, 1589:1023-30.

Zellweger, R, Wichmann, MW, Ayala, A, Chaudry, IH, 998: Metoclopramide: A novel and safe immunomodulating agent for restoring the depressed macrophage immune function after hemorrhage. J. Trau. Acute Care Surg. 44, 1, at: https://journals.lww. com/jtrauma/Fulltext/1998/01000/Metoclopra-mide.

\section{Explanation of figures}

Fig.1. Brain (stained with $\mathrm{H} \& \mathrm{E}$, x1000) represents A. negative-control (GI). B. positive-control (GII) arrow pointed to a tachyzoite. C. chlorpromazine infected treated (GVI). D. clozapine infected treated (GVII) circle surround eosinophilic cell. E. metoclopramide infected treated (GVIII).

Fig. 2: Mean dopamine level among groups.

Fig. 3: Mean INF-Y Level among groups.

Fig. 4: Mean prolactin level among groups.
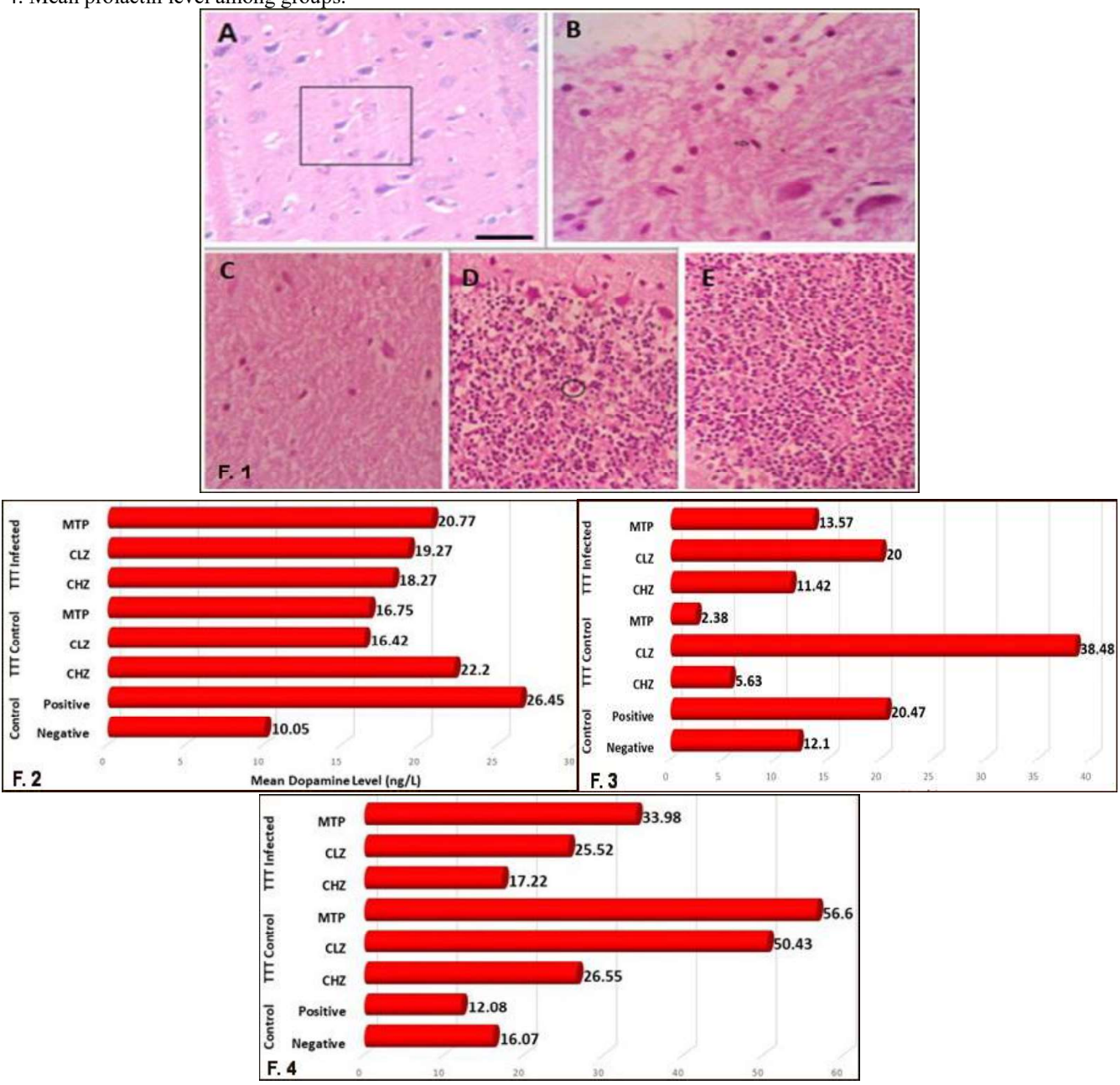